\title{
Flood risk management in Flanders: from flood risk objectives to appropriate measures through state assessment
}

\author{
Sven Verbeke ${ }^{1, a}$ and Neel Devroede ${ }^{2}$ \\ ${ }^{1}$ Flanders Environment Agency, Zandvoordestraat 375, 8400 Ostend, Belgium \\ ${ }^{2}$ Flanders Environment Agency, Koning Albert-Il laan 20 bus 16, 1000 Brussels, Belgium
}

\begin{abstract}
In compliance with the EU Flood Directive to reduce flood risk, flood risk management objectives are indispensable for the delineation of necessary measures. In Flanders, flood risk management objectives are part of the environmental objectives which are judicially integrated by the Decree on Integrated Water Policy. Appropriate objectives were derived by supporting studies and extensive consultation on a local, regional and policy level. Under a general flood risk objective sub-objectives are formulated for different aspects: water management and safety, shipping, ecology, and water supply. By developing a risk matrix, it is possible to assess the current state of flood risk and to judge where action is needed to decrease the risk. Three different states of flood risk are distinguished: a) acceptable risk, where no action is needed, b) intermediate risk where the risk should be reduced by cost efficient actions, and c) unacceptable risk, where action is necessary. For each particular aspect, the severity of the consequences of flooding is assessed by quantifiable indicators, such as economic risk, people at risk and ecological flood tolerance. The framework also allows evaluating the effects of the implemented measures and the autonomous development such as climate change and land use change. This approach gives a quantifiable assessment of state, and enables a prioritization of flood risk measures for the reduction of flood risk in a cost efficient and sustainable way.
\end{abstract}

\section{Introduction}

The region of Flanders, the Flemish speaking part of Belgium, is a densely populated and vulnerable area when it comes to flood risk. Still recently, in July 2005, July 2007, November 2010, and January 2015 several water level records were established. Economic development and climate change with wetter winters and more extreme rainfall events in summer will make Flanders an even more flood prone area.

Therefore, sustainable measures are necessary to reduce flood risk. In compliance with the EU Flood Directive [1], both the likelihood and the consequential damage of floods are addressed through a mix of protective, preventive and preparedness measures. The so-called Multi-layered Water Safety [2] serves as a basis for the flood risk management in Flanders.

Flood risk objectives are indispensable for the delineation of the necessary measures. As illustrated in figure 1 , this paper describes the process of the derivation of flood risk objectives and how they are used in the compilation of measures. Based on the vision of the Multi-layered Water Safety a proper flood risk analysis leads to proper flood risk objectives, from where area specific flood risk matrices are created. The flood risk matrix serves as a framework to discriminate between

\footnotetext{
a Sven Verbeke: s.verbeke@vmm.be
}

different quantifiable states. This state assessment guides the prioritization and delineation of necessary measures.

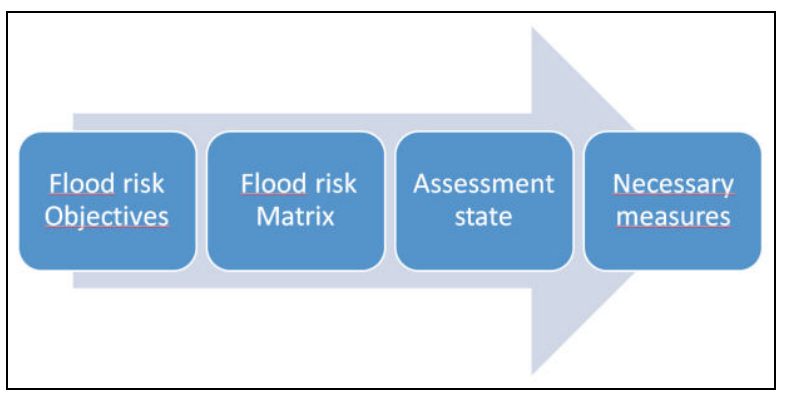

Figure 1. Process from flood risk objectives tot necessary measures

\section{Flood risk objectives}

\subsection{Implementation process}

\subsubsection{Competent authority}

The Coordination Committee on integrated Water Policy (CIW) [3], composed of different administrations 
involved in water management, is the competent authority. It plays a key role in the preparation, planning and monitoring of integrated water policy in the Flemish Region. Its task includes the drafting and coordination of the flood risk management plans (FRMP), which are judicially integrated in the river basin management plans (RBMP) by the Decree on Integrated Water Management $[4,5]$.

\subsubsection{Implementation process}

Figure 2 illustrates the organizational and legal implementation process of the flood risk objectives in Flanders.

The Flanders Environment Agency and the Department of Mobility and Public Works started up a supporting study [6] which elaborates environmental objectives, specifically aimed at managing floods and water shortages. The study started with an inventory for which different authorities representing relevant sectors (agriculture, nature, water management, cultural heritage) were questioned. After the inventory, a risk matrix or framework, in which different objectives can be weighted, was worked out. This happened on a regional scale and was refined on a local scale by working out 3 test cases.

Another supporting study from the Flanders Environment Agency, in support of the flood risk management plan [7], provided flood risk results in terms of economic and social risk. Two corresponding quantifiable indicators (economic risk and People At Risk or $\mathrm{P} @ \mathrm{R}$ ) were developed and can be used to fill in the risk matrix.

Those rather technical and academic studies were used as a basis for the policy approach. Representatives of water managers and other public authorities translated those results into generally accepted objectives and into a framework that can be used by policy decision makers. The definite flood risk objectives are the result of an intensive participation process between stakeholders by organising several workshops and taskforces on a local, regional, public and policy level. In December 2013 the definite objectives were approved by the CIW.

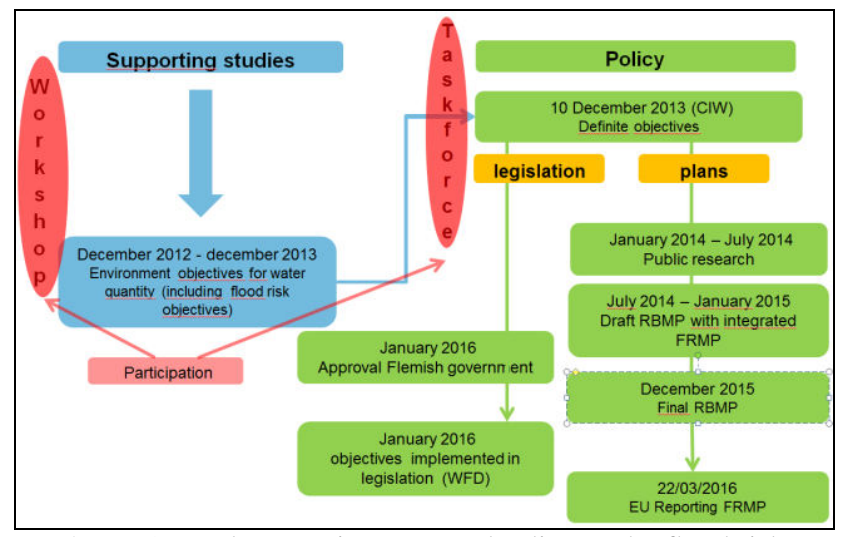

Figure 2. Implementation process leading to the flood risk objectives and its judicial integration and the integration in the river catchment plans with the integrated flood risk management plans
After the approval of the objectives, two implementation strategies were followed in order to establish a vigorous (legal) policy. The first way is by integrating the objectives in legislation [8], the second way by implementing the objectives into the RBMP with the integrated FRMP. In January 2016 the Flemish Government approved the judicial integration of the flood risk objectives, in February 2016 it appeared in the Belgian Bulletin of Acts, The implementation of the objectives and risk matrices in the RBMP's was approved by December 2015, in March 2016 the FRMP were reported to Europe.

This approach favours a generally accepted and sustainable framework of quantifiable objectives useful for the reduction of the flood risk in Flanders.

\subsection{Flood risk management objectives}

The flood risk management objectives are aimed at the reduction of the adverse consequence of floods. For the formulation, the following conditions are taken into account:

- Testable, in a way the state assessment can be done;

- Realistic, in a way the objectives are attainable;

- Ambitious and powerful, in a way a higher flood risk safety can be realised;

- Acceptable, in a way all responsible authorities can agree.

Firstly, an overall flood risk objective is determined. Secondly, beneath that general objective, several aspect related sub-objectives are formulated.

The coordinating flood risk objective aimes at a sustainable flood risk reduction with benefits for people, economic activity, ecology and cultural heritage. To reach that sustainable reduction, an optimal combination of protective, preventive and preparatory measures is taken into account. The supporting study [7] showed that investments in protective measures are still necessary as they can significantly reduce flood risk in high risk regions. Preparedness (flood prediction and warning systems) is almost always a cost effective investment. But prevention showed to be essential for an effective flood risk management in Flanders. Almost in every assessed catchment a combination of all three types of measures was the optimal solution for efficient flood risk reduction.

With measures geared to an optimal cost benefit ratio, at least the effects of the autonomic development such as climate change and land use change are compensated.

Under the overall objective, sub-objectives are defined for the following aspects:

- Water management and safety;

- Shipping;

- Ecology;

- Water supply.

These aspects are important for the government in realising their policy. Every public and private sector can 
be linked to those aspects. The following sub-objectives were determined through aiming at:

- Water management and safety: a sustainable and durable reduction of the economic damage and people at risk;

- Shipping: buffering and appropriate transport to consolidate shipping, unless safety precautions oblige a hitching;

- Ecology: high water flows compatible with the achieving of the good ecological state or potential as defined in the Water Framework Directive [9]

- Water supply: avoiding any day with shortage of drinking water, meant for the production of drinking water for human consumption, because of pollution of rough water by flooding water. The entrance to the water production centres is guaranteed as much as possible.

Those (sub-)objectives are defined on a coordinating Flemish scale without weighing them against each other. This means that on a generic scale all objectives are equally valued. For a specific situation the objectives will be weighed depending on the area-specific characteristics.

The EU Flood Directive doesn't specify a time horizon for reaching the objectives. The uncertainty in future climate change projections and land use development, and the fact it takes quite some time and means to reduce the flood risk, it's not easy to point a specific deadline. Despite those uncertainties, the supporting study [7] determined that measures can be implemented by 2050 with regular budgets. Therefore, in Flanders a gradual transition to the multi-layer water safety with the realization of the flood risk objectives is foreseen in 2050 .

\section{Assessment of state}

\subsection{Risk matrix}

Risk matrices are used to assess or evaluate the flood risk in a specific catchment. For the aspects of water management and safety, and ecology (Figure 3), the frequency of flooding is related to the severity of consequences (risk $=$ probability $\mathrm{x}$ consequences) going from negligible to catastrophic. For the aspect of water supply a slightly different matrix is used (Figure 4): the severity of consequences of flooding to the drinking water production centres is related to the shortage due to flooding. No risk matrix is used for the aspect of shipping because safety precautions have priority.

3 states are distinguished:

- State A: acceptable risk, no action needed to improve the situation;

- State B: intermediate risk to be improved by cost efficient measures;

-State C: unacceptable risk, action must be undertaken.

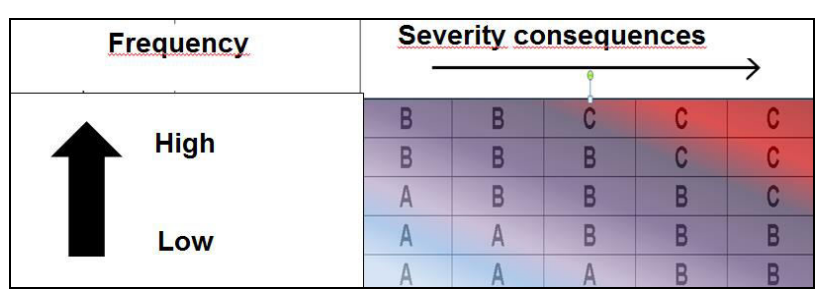

Figure 3. Flood risk matrix relating the frequency of flooding to the severity of the consequence (aspect water management and safety, and ecology)

Those frameworks of evaluation are worked out for every basin in Flanders. It enables the decision making where action is needed to obtain the flood risk objectives, and allows a follow up of the evolution of the state throughout the years. In that way, the impact of the executed measures and the autonomous development such as climate change can be checked.

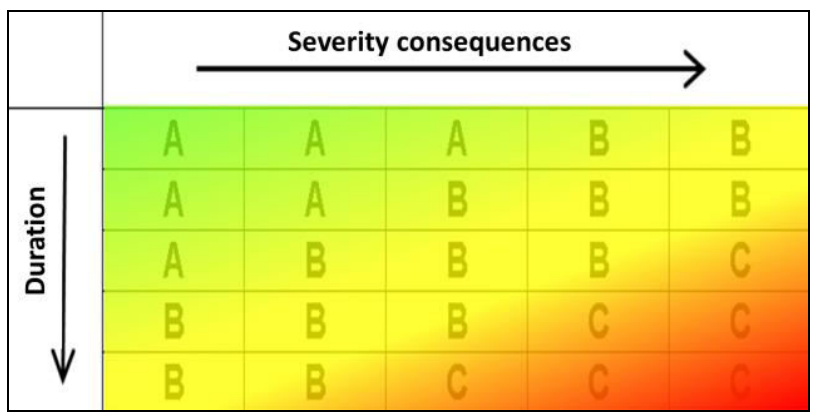

Figure 4. Flood risk matrix relating the frequency of flooding to the severity of the consequence (aspect water supply)

\subsection{Indicators}

As part of the risk matrix, several indicators are used to quantify and categorize the severity of flooding. Table 1 shows the indicators for the aspect of water management and safety, ecology and water supply. As stated before, no indicator is defined for shipping due to the dominance of safety precautions.

People at risk is an indicator that quantifies the amount of people affected by floods, not casualties. For this purpose, population data is crossed with flood hazard maps with a high (return period $\mathrm{T}$ approximately 10 years), medium ( $\mathrm{T}$ approx. 100 years) and low ( $\mathrm{T}$ approx. 1000 years) probability of flooding. The economic damage $\left(€ / \mathrm{m}^{2}\right)$ is deduced from flood hazard maps and the Flemish land use map. Damage calculation were done using the LATIS-software [10]. 


\begin{tabular}{|l|l|l|}
\hline Aspect & $\begin{array}{l}\text { Objective }= \\
\text { aiming at... }\end{array}$ & Indicator \\
\hline $\begin{array}{l}\text { Water } \\
\text { management and } \\
\text { safety }\end{array}$ & $\begin{array}{l}\text { Sustainable } \\
\text { reduction flood } \\
\text { risk }\end{array}$ & $\begin{array}{l}\text { People at risk and } \\
\text { economic damage }\end{array}$ \\
\hline Ecology & $\begin{array}{l}\text { High flows } \\
\text { compatible with } \\
\text { good ecological } \\
\text { potential or state }\end{array}$ & Flood tolerance \\
\hline Water supply & $\begin{array}{l}\text { No shortage } \\
\text { drinking water }\end{array}$ & $\begin{array}{l}\text { Amount and days } \\
\text { of shortage rough } \\
\text { water }\end{array}$ \\
\hline
\end{tabular}

Table 1. Quantifiable indicators for water management and safety, ecology and water supply

For the aspect of ecology the flood tolerance of vegetation within nature conservation areas with a high probability of flooding is investigated. For medium and low probability flood prone areas it's been assumed that no permanent damage is caused.

The developed indicators are a result of a lot of consultation and participation with representatives of water managers and other public authorities within the CIW, and reflect the current insights into the complex matter of evaluating environmental objectives. Therefore those indicators and their thresholds, applicable in whole of Flanders, aren't necessarily fixed, but can be optimized or adapted throughout the coming years.

The assessment of state reveals the severity of the flood risk in a certain region and enables the competent authority to make a well-considered decision.

The FRMP contains hundreds of measures aiming at a flood risk decrease in Flanders. Those measures consist of an optimal mix of protective, preventive and preparedness measures, in which all actors in flood risk management face up to their responsibility (so-called multi layered water safety). Some examples are: holding and storing of water (protection), avoiding and removing (new) buildings in flood prone areas (prevention) and raising public awareness (preparedness). In order to sort out those numerous measures in different catchments, it's necessary to prioritize those measures.

\subsection{Results}

\subsubsection{Some examples of risk matrices}

Figure 5 till 7 show risk matrices for different catchment areas in Flanders.

The first matrix, the evaluation of economic damage in the catchment of the Polders of Bruges (Figure 5), shows that the damage caused by floods with a high probability or high frequency ( $\mathrm{T}$ approximately 10 years) is serious ( 5 million euro/year). The damage becomes critical with approximately 300 and 700 million euro/year respectively due to floods with a medium (T approx. 100 years) and low probability ( $\mathrm{T}$ approx. 1000 years). For the economic damage, we can conclude that the catchment is in a state of intermediate risk (state B) (purple zone), and the situation should be improved by cost efficient measures.

The indicator indicating people at risk (no casualties) shows a critical situation for high probability floods, and a catastrophic one for medium probality floods. The catastrophic consequences of the low probability floods are still within the intermediate riskzone. Because the probability is so low that the catastrophic consequences (60.000 people at risk) doesn't result in a significant risk. But the catastrophic consequences of the medium probability is an unacceptable risk (red zone) and has to be improved by all means. The high numbers of economic damage and $\mathrm{P} @ \mathrm{R}$ is caused by flooding of the sea at medium and low frequency.

\begin{tabular}{|c|c|c|c|c|c|}
\hline Probability & Negligible & Marginal & Severe & Critical & Catastrophic \\
\cline { 2 - 6 } economic damage & $<0.1$ & $>0.1$ & $>2$ & $>50$ & $>10000$ \\
\hline High & & & 5 & & \\
\hline $\begin{array}{c}\text { Medium } \\
\text { Low }\end{array}$ & & & & 295 & \\
\hline & & & & & \\
\hline Probability & Negligible & Marginal & Severe & Critical & Catastrophic \\
\cline { 2 - 6 } people at risk & $<5$ & $>5$ & $>100$ & $>2500$ & $>25000$ \\
\hline High & & & 185 & & \\
\hline Medium & & & & & 26551 \\
\hline Low & & & & & 60179 \\
\hline
\end{tabular}

Figure 5. Evaluation of flood risk for economic damage (mio $€ / \mathrm{m}^{2}$ ) (top figure) and people at risk (bottom figure) in the catchment of the Polders of Bruges

The ecologic flood tolerance in the catchment of the Nete (Figure 6) for high probability floods is quite good. Only a small area of 12 ha of nature conservation area is very sensitive to flooding In this catchment we can conclude that the situation is partly acceptable (zone A), where no action is needed. In the other areas (zone B) the situation has to be improved by cost efficient measures.

\begin{tabular}{|c|c|c|c|c|c|}
\hline \multirow[b]{2}{*}{ Frequency } & \multicolumn{4}{|c|}{ Seriousness: score flood tolerance ${ }^{[11]}$} & \multirow[b]{2}{*}{$0-0.6$} \\
\hline & $2.4-3$ & 2.4-1.8 & 1.2-1.8 & $0.6-1.2$ & \\
\hline & Tolerant & \multicolumn{2}{|c|}{ Intermediary } & & $\begin{array}{l}\text { Very } \\
\text { sensitive }\end{array}$ \\
\hline High & 193 & 524 & 5 & 357 & 12 \\
\hline Medium & & & & & \\
\hline Low & & & & & \\
\hline
\end{tabular}

Figure 6. Evaluation of flood risk for flood tolerance in nature areas in the catchment of the Nete

In the cathment of the Dender, Figure 7 illustrates the years with water shortage related to the amount of the shortage of rough water due to flooding and its duration. Here we can conclude that -for the investigated years- the situation is acceptable (zone A) and no action is needed. 


\begin{tabular}{|c|c|c|c|c|c|c|c|c|c|}
\hline & & Size of shortage $\%$ & Irinking-water se & ector & & & & & \\
\hline & & 1 & 2 & 5 & 10 & 25 & 50 & 75 & 100 \\
\hline \multirow{7}{*}{ 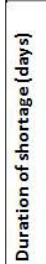 } & 0 & $\begin{array}{l}2009-2010-2011- \\
2012-2013\end{array}$ & & & & & & & \\
\hline & 2 & & & & & & & & \\
\hline & 5 & & & & & & & & \\
\hline & 10 & & & & & & & 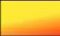 & Da \\
\hline & 20 & & & & 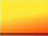 & 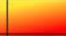 & 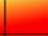 & & \\
\hline & 25 & & $x_{2}$ & & & & & & \\
\hline & $>50$ & +2 & & & & & & & \\
\hline
\end{tabular}

Figure 7. Evaluation of shortage rough water due to flooding in the catchments of the Dender

\subsubsection{Evaluation of state in Flanders}

The spatial distribution in Flanders of people at risk is illustrated in figure 8 . The figure shows an evenly scattered pattern for high probability floods. Due to risk of flooding by the sea, the catchments nearest to the sea (Yser, Polders of Bruges, Lower Scheldt) have a larger share of the affected people at medium or low probability (or medium or high return period). All of the catchments, except one, are situated in state B. So, cost efficient measures have to be undertaken to improve the situation. Only the catchment of the Polders of Bruges has an unacceptable risk for the people at risk indicator, as illustrated in Figure 5. As a result, the compelling measure of the Coast Safety Plan [12] is a work in progress. The spatial distribution of economic damage gives similar results as people at risk.

For the aspect of ecology, we can conclude that in all catchments the situation has to be improved by costefficient measures.

Concerning the aspect of water supply, we can conclude -for the investigated years- that the situation is acceptable in all catchments, except one. In the catchment of the Nete (state B), if possible, cost efficient measures must be undertaken to improve the situation.

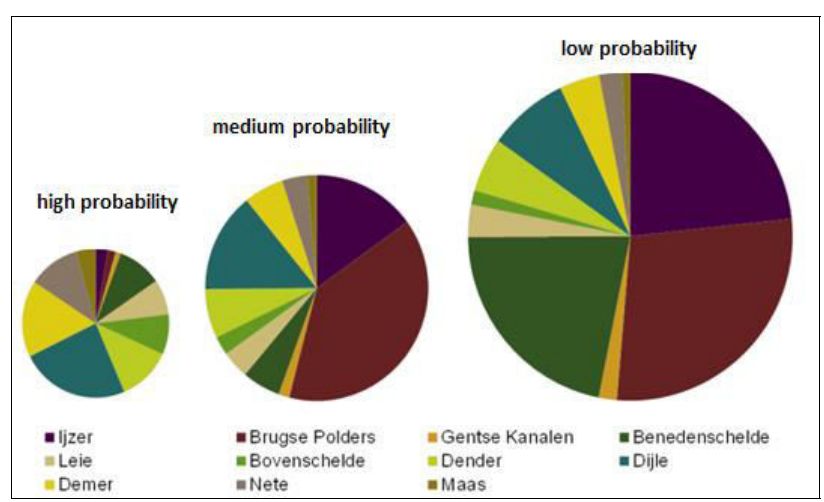

Figure 8. Contribution of catchment in terms of percentage in Flanders due to flooding with a low, medium and high probability

\section{Prioritization measures}

In compliance with the EU Flood Directive [1], a prioritization of measures is necessary. A wellconsidered classification can ease the choice in relation to the available means and finances. A prioritization ensures a faster and successful realisation of the flood risk objectives.

The schematisation of prioritization is given in Figure 9. The prioritization of flood risk measures start from an already performed prioritization within the scope of the WFD [9]. The criteria used for the prioritization within the WFD are cost efficiency, feasibility, economic analysis, and urgency. The prioritization results in a classification in 2 classes relative to the plan cycles of the RBMP:

- Class 1 actions with a high priority and to be executed between 2016 and 2021;

- Class 2 actions will be executed in the next RBMP cycle(s) $(2021-\ldots)$

For the final flood risk prioritization, all flood risk management measures were retained and a further prioritization was performed using social flood risk as a criterion. This is illustrated in figure 10. From the flood risk maps in Flanders, all subcatchments - i.e. smaller catchments - were sorted according to people at risk integrated over low, medium and high probability floods. Then, a subdivision was made into 2 categories: high and low social risk. The subcatchments with the 50 percent highest number of people get a higher social risk score, the other 50 percent represent a lower social risk.

The combination of the social risk score (high or low) with classes ( 1 or 2 ) provides a final prioritized list of measures belonging to a class of high, middle or low priority. Class 1 measures within a high social risk subcatchment get the highest priority, class 2 measures within a low social risk subcatchtment the lowest priority.

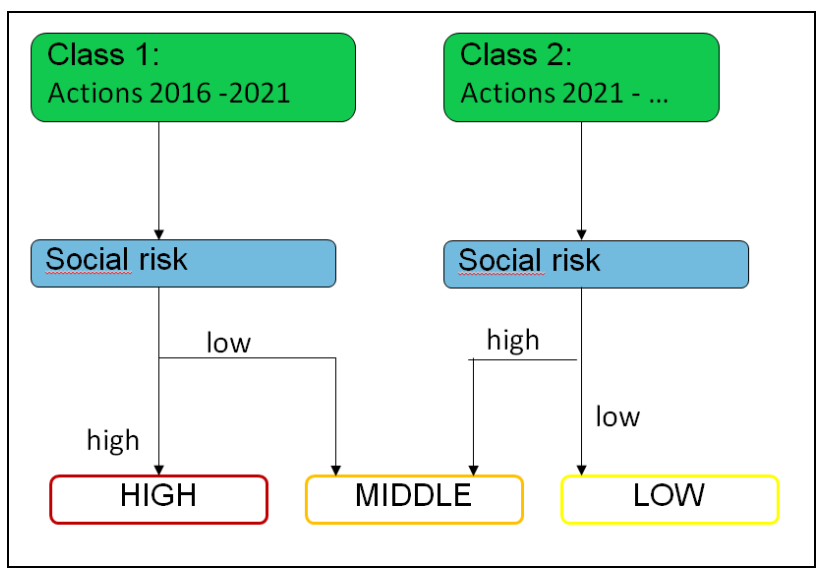

Figure 9. Scheme for the prioritization of flood risk measures.

This list indicates which actions should be executed firstly. Nevertheless, new insights, changing circumstances, technical feasibility, and the presence or absence of a local social support can influence the realization and the timing of a measure. 


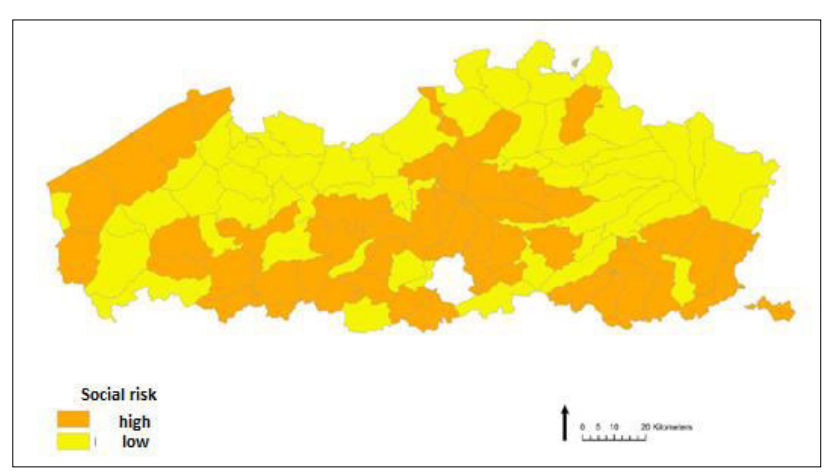

Figure 10. Spatial distribution of social risk (people at risk) in Flanders

\section{Conclusion}

Flanders is a highly flood prone region. Therefore a uniform framework is developed to delineate and prioritize the necessary measures that are needed for a significant reduction of the flood risk.

By supporting studies and a lot of consultation and participation, flood risk objectives and sub-objectives were determined. Sub-objectives, all equally important on a regional scale, were developed for the aspects water management and safety, shipping, ecology, and water supply, The judicial anchoring of the flood risk objectives and sub-objectives and their implementation in the FRMP, which are integrated in the RBMP, generates a generally accepted and sustainable framework useful for reducing the flood risk in Flanders.

For all catchments in Flanders risk matrices are used to assess and evaluate the state of flood risk in a specific catchment. The evaluation distinguishes 3 states, going from acceptable, where no action is needed, to unacceptable, where action has to be undertaken. It stresses the severity of the flood risk situation in a certain region, enables to judge where action is needed to achieve the flood risk objectives, and enables the competent authority to make a well-considered choice or selection of measures.

Building on the executed classification within the WFD, an the additional prioritization is performed with social risk (people at risk) as the criterion. This prioritization indicates which actions should be executed firstly to achieve the flood risk objectives.

This process from flood risk objectives to appropriate measures, results in an objective and quantifiable insight of the severity of flood risk today and tomorrow, and clarifies where and which measures should be executed firstly. With this method, Flanders can face the uncertain future of flood risk and the reduction of flood risk with confidence.

\section{References}

1. Directive 2007/60/EC of the European Parliament and of the Council of 23 October 2007 on the assessment and management of flood risks; http://eur-lex.europa.eu/legalcontent/EN/TXT/?uri=CELEX:32007L0060

2. Coordination Committee on Integrated Water Management, Flemish Government, Multi-layered Water Safety (2015): www.hoogwaterzonderkater.be

3. Coordination Committee on Integrated Water Management: www.integraalwaterbeleid.be

4. Decreet betreffende het Integraal Waterbeleid (18/07/2003);

http://codex.vlaanderen.be/Zoeken/Document.aspx?

$\mathrm{DID}=1011715$ \&param=inhoud\&ref $=$ search

5. River basement management plans with the integrated flood risk management plans (2015): www.volvanwater.be

6. Antea , Department of Mobility and Public Works, Flanders Environment Agency (2013). Milieukwantiteitsdoelstellingen voor oppervlaktewater.

7. IMDC, Flanders Environment Agency (2013). Onderbouwing van het Overstromingsrisicobeheerplan van de onbevaarbare waterlopen.

8. Belgian Bulletin of Acts, Orders and Decrees (3 February 2016). Besluit van de Vlaamse Regering tot wijziging van het besluit van de Vlaamse Regering van 1 juni 1995 houdende algemene en sectorale bepalingen inzake milieuhygiëne, wat betreft criteria voor overstromingsrisicobeheerdoelstellingen en oppervlaktewatertekortbeheerdoelstellingen. http://www.ejustice.just.fgov.be/mopdf/2016/02/03 1.pdf\#page $=47$

9. Directive 200/60/EC of the European Parliament and of the Council of 23 October 2000 establishing a framework for Community action in the field of water policy. http://eur-lex.europa.eu/legalcontent/EN/TXT/?uri=CELEX:32000L0060

10. Deckers P., Broidioi S., Verwaest T., De Maeyer P, Mostaert F. (2013). LATIS : van overstromingskaarten naar schadekaarten en risicokaarten.. Jaarboek De Aardrijkskunde 2013.

11. Debie (2009). Scores flood tolerance from INBO (Institute for nature ans forest investigation) model oversTol_kwantiteit

12. Agentschap voor Maritieme Dienstverlening en Kust. Geïntegreerd Kustveiligheidsplan. http://www.vlaamsebaaien.com/geintegreerdkustveiligheidsplan 